


\section{Criando danças com crianças e professores(as) em formação}

Neila Cristina Baldi

Recebido em: 19/05/2019

Aprovado em: 04/06/2019

DOI: $10.5965 / 2358092521212019027$ 


\section{RESUMO}

O presente artigo discute proposições de dança com crianças, que foram pesquisadas tanto na educação básica quanto no ensino superior, com professores(as) em formação. Apresenta a proposta metodológica Espiral do/no Movimento/Conhecimento, que nasce de estudos individuais empíricos no início dos anos 1990, mas que foi desenvolvida no Doutorado em Artes Cênicas, em 2017, pela Universidade Federal da Bahia (UFBA). A metodologia tem como aportes teóricos-práticos a Educação Somática (a partir do Sistema Laban/Bartenieff e da Coordenação Motora) e o Construtivismo Pós-Piagetiano. A proposta se baseia na tríade de conteúdos: dança-expressividade-estrutura corporal, e em quatro eixos metodológicos: (re)conhecer, (re)significar, explorar e conceituar. Além disso, se propõe a discutir práticas pedagógicas nas infâncias, a partir da gestação de um espetáculo de dança com crianças, desenvolvido dentro do Programa Institucional de Bolsas de Iniciação à Docência (PIBID), com referência nas pesquisas de Manoel Sarmento (interatividade, ludicidade, fantasia do real e reiteração), e na metodologia discutida.

Palavras-chave: dança; infâncias; metodologia de dança.

Jean Piaget (1987) dizia que a primeira forma de conhecimento da criança era a cinestésica - ou o chamado período sensório-motor. Segundo o epistemólogo suíço, o desenvolvimento da inteligência humana se dava por estágios, em uma espiral, que podiam ser acionados em fases distintas. Ou seja, não era porque a pessoa chegava ao estágio do raciocínio formal $^{1}$ que não poderia mais agir a partir do sensório-motor. A

1 Piaget, ao acompanhar o desenvolvimento da construção do conhecimento, denominou as fases pelas quais esta construção passava de esquemas ou estágios. Segundo ele, são quatro estágios de desenvolvimento: sensório-motor (até os dois anos, quando a criança lida com a realidade a partir dos sentidos e de atividades motoras), pré-operatório (até os sete anos, quando desenvolve 
partir do conhecimento acerca do Construtivismo Pós-Piagetiano (ou seja, do desenvolvimento da Epistemologia Genética e seus desdobramentos posteriores), comecei a repensar o aprender e o ensinar dança para crianças, ainda nos anos 1990, quando era professora no ensino primário (atualmente ensino Fundamental I).

Nos anos 2000, passei a desenvolver trabalhos voluntários com dança para crianças e, nestes, de forma empírica, a pesquisar formas outras de aprender e ensinar, que culminaram com a graduação em Dança, Mestrado e Doutorado em Artes Cênicas, no qual desenvolvi a proposta metodológica Espiral do/no Movimento/Conhecimento, parte de aportes teóricos da Educação Somática e do Construtivismo Pós-Piagetiano. Paralelamente, na década passada, fui professora de Dança na educação básica e, desde 2013, formadora de professoras e professores, em cursos de Licenciatura em Dança, nos quais trabalho com Didática e Metodologia da Dança, na Bahia, e Práticas Educativas, mais recentemente, no Rio Grande do Sul, com ênfase nas infâncias ${ }^{2}$. Aliado a isso, nos últimos dois anos, coordeno o Programa Institucional de Bolsas de Iniciação à Docência, no qual desenvolvo ações de Dança na pré-escola e no ensino fundamental.

É a partir deste acúmulo de experiência em Dança com crianças que discuto, neste artigo, a dança nas infâncias: processos artísticos e pedagógicos na escola e em organizações não-governamentais. Que modos de criar danças temos produzido nestes espaços, a partir das pesquisas desenvolvidas nas Universidades? Apresento e discuto aqui a proposta metodológica Espiral do/no Movimento/Conhecimento, bem como

a linguagem, constrói sistemas mágicos de crenças e desenvolve atividades racionais), operatório-concreto (até os 12 anos, quando percebe o pensamento da outra pessoa, consegue cooperar, usam referências externas e conseguem reverter o pensamento) e raciocínio formal (a partir dos 12 anos, quando resolve problemas a partir do pensamento e não da ação, possui pensamento lógico e abstrato). Apesar de delimitar a faixa-etária em que surgem, o teórico afirma que durante a vida podemos operar com eles alternadamente.

2 Na Universidade Estadual do Sudoeste da Bahia (UESB), na qual fui professora do Curso de Licenciatura em Dança, no período de 2013 a 2016; e na Universidade Federal de Santa Maria (UFSM), na qual sou professora do Curso de Dança-Licenciatura desde 2017. 
a gestação de um espetáculo de dança com/para infâncias dentro do Programa Institucional de Bolsas de Iniciação à Docência (PIBID).

\section{ESPIRAL DO/NO MOVIMENTO/CONHECIMENTO}

Em dança, apesar de se trabalhar com o movimento - o que significaria construção de conhecimentos cinestésicos nem sempre há o privilégio à cinestesia na aprendizagem. O ensino da dança tem se pautado, na maioria das vezes, na demonstração de movimentos por parte dos(as) professores(as) e na cópia pelos(as) alunos(as), independentemente da faixa-etária. Ou seja, aprende-se pelo movimento sem 'senti-lo'. E, se, as aulas são de uma técnica codificada - como o balé clássico ou o jazz -, a única diferença entre as classes para jovens e crianças é um elemento de ludicidade. Mas o(a) professor(a) segue sendo o centro e a criança, a copiadora de movimento. Como se a ela não lhe fosse possível criar...

Além de repetir um modelo semelhante ao do(a) aprendiz adulto(a), o(a) professor(a) de dança na educação infantil não considera também aquilo que Sarmento (2003) chama de culturas da infância, que estão alicerçadas em quatro eixos: a interatividade - atividades, rotinas, valores e preocupações que produz com outras crianças e adultos - a ludicidade - brincar consigo, com os(as) outros(as) e com objetos -, a fantasia do real - o mundo do faz de conta - e a reiteração - começar tudo de novo, sem linearidade temporal. Ou seja, propõe-se uma dança que não respeita as peculiaridades das infâncias, uma dança que se considera para e não com.

Meus estudos sobre o Construtivismo Pós-Piagetiano, nos anos 1990, fizeram-me repensar o aprender e ensinar dança. Naquela época, eu era professora do ensino primário e, ao alfabetizar de maneira outra que o modo como fui alfabetizada (a partir da cartilha da abelhinha), acabei revendo minha relação com o balé clássico - dança que praticava na ocasião. Se eu alfabetizava a partir do Construtivismo Pós-Piagetiano, como seria 
"alfabetizar" o balé a partir dele também? De modo incipiente, iniciei experimentos com dança clássica para crianças a partir da ludicidade, mas ainda não propunha uma dança com crianças. Na graduação em Dança, anos mais tarde, passei a pesquisar o uso de histórias dançadas nas infâncias, bem como a pesquisa de movimento das crianças nas aulas de dança. Começava, então, a valorizar alguns dos eixos elencados por Sarmento (2003).

Posteriormente, inicialmente a partir do balé clássico, fui desenvolvendo a proposta metodológica aqui apresentada, que tem como pressupostos teóricos a Educação Somática ${ }^{3}$ e o Construtivismo Pós-Piagetiano. Nesta abordagem, os conteúdos de dança aparecem na tríade dança-expressividade-estrutura corporal e são trabalhados em procedimentos dentro dos eixos (re) conhecer, (re)significar, conceituar e explorar. Como uma espiral, um eixo leva ao outro, sem hierarquia. A metodologia foi desenvolvida no Doutorado em Artes Cênicas. Nesta época, ainda antes mesmo da conclusão do mesmo, percebi - a partir das práticas das disciplinas de Didática e Metodologia de Ensino de Dança, que realizava em escolas de Educação Infantil, bem como dos estágios supervisionados de minhas aulas, que a proposta metodológica que vinha desenvolvendo não precisava apenas e tão somente ser realizada com o balé clássico, mas podia ser praticada em aulas de dança na escola. Foi o que propus ali e, posteriormente, em trabalho voluntário, em uma Organização Não-Governamental em Porto Alegre, com crianças, quando voltei para o Rio Grande do Sul ${ }^{4}$. Durante este período passei a entender que trabalhava o aprenderensinar ${ }^{5}$ dança, criando dança com crianças. Ou seja, não propunha mais uma dança para crianças...

Para o Construtivismo Pós-Piagetiano, o conhecimento se

3 Aqui refiro-me às categorias Corpo e Expressividade, do Sistema Laban/ Bartenieff, bem como à abordagem Coordenação Motora, de Marie-Madeleine Béziers. Além disso, a proposta metodológica tem como base os seguintes princípios somáticos: privilégio à informação que vem do corpo, descoberta pessoal, autorregulação, corpo saudável, mudança de ritmo e integração.

4 Na UESB, em Jequié (BA), e na Ocupação Pandorga, em Porto Alegre (RS).

5 Para Paulo Freire (1996, p. 24): “Aprender precedeu o ensinar ou, em outras palavras, ensinar se diluía na experiência realmente fundante de aprender." A partir desse pressuposto e apoiada em Carmen Lúcia Pérez e Carmen Sanches Sampaio (2012), proponho o aprenderensinar juntos. 
dá a partir da tensão: equilíbrio-desequilíbrio, ou seja, ao entrar em contato com algo que o desequilibra, a pessoa vai buscar um novo equilíbrio e assim sucessivamente. Este jogo de tensões, de acordo com Piaget, se dava na assimilação - aquilo que provoca o desequilíbrio - e na acomodação - o que permite o equilíbrio:

[...] as coisas nunca são conhecidas em si mesmas, porquanto esse trabalho de acomodação só é possível em função do processo inverso de assimilação. [...] Ora, esses dois aspectos do pensamento são indissociáveis: é adaptando-se às coisas que o pensamento se organiza e é organizando-se que estrutura as coisas. (PIAGET, 1987, p. 18-19)

Para Piaget, o desequilíbrio é um conflito cognitivo que permite, inclusive, que a pessoa aprenda com seus erros. Pensar na aprendizagem a partir do Construtivismo Pós-Piagetiano é, portanto, pensar que não existem jeitos certos de se fazer, pois as construções são dinâmicas, o que pareceria certo hoje, amanhã será desequilibrado por um conflito e nascerá um outro modo de se fazer/pensar/agir. Segundo Susan Stinson (1999, p. 30):

Um entendimento dos sistemas destes diferentes estágios pode nos ajudar a explicar o comportamento das crianças como um guia para ensinarmos dança. Em segundo lugar, é importante que entendamos que a desequilibração é a base do processo de aprendizado. [...] Devemos oferecer oportunidades para o aspecto dual da acomodação - encontrar novos desafios, resolver problemas - e da assimilação - repetição, prática, fazer daquilo algo que seja nosso. (grifo da autora).

Em dança, não pensar em um jeito 'certo', nos permite investigar a pesquisa de movimento e os modos outros de dançar. Permite ver danças em movimentos cotidianos, em movimentos não usuais. Permite repensar a dança, e não apenas o modo de aprender e ensinar.

Por outro lado, a Educação Somática - “[...] um termo guarda-chuva usado para juntar experiências práticas corporais que 
privilegiam experiências subjetivas ${ }^{6}$." (FORTIN, 2002, p. 128) e que abrange desde técnicas criadas no século passado até seus desdobramentos, com abordagens - tem como princípios: o privilégio à informação que vem do corpo, a descoberta pessoal, a autorregulação, o reconhecimento de padrões, a busca por um corpo saudável7 , a mudança de ritmo e a integração (BALDI, 2014). A partir dessas premissas foi construída a proposta Espiral do/no Movimento/Conhecimento.

A proposta metodológica parte da tríade de conteúdos: dança-expressividade-estrutura corporal e dos eixos (re)conhecer, (re)significar, explorar e conceituar. Além dos fundamentos da dança - gerais ou de uma técnica específica - são trabalhados conteúdos do Sistema Laban/Bartenieffo relativos à expressividade - fatores do movimento, impulsos e estados expressivos - bem como ligados à anatomia, a partir da abordagem Coordenação Motora, de Marie-Madeleine Béziers ${ }^{9}$. O que interessa é que todos os conteúdos da tríade sejam integrados, ou seja, por exemplo, se a ênfase do trabalho está no alinhamento dos pés são enfocados movimentos dançados com esta parte.

Geralmente as aulas começam pelos eixos explorar ou (re) conhecer. As explorações partem de verbos - ações de $\operatorname{Laban}^{10}$, ações cotidianas etc. - ou seja, que partes do corpo dobram, lançam, estendem, deslizam etc. Posteriormente, podem ser sorte-

6 "[...] an umbrella term used to assemble experiential bodily practices that privilege subjective experience." (FORTIN, 2002, p. 128).

7 Aqui saudável globalmente, pois não há separação corpo e mente.

8 O que chamamos de Sistema Laban/Bartenieff é o desdobramento das pesquisas iniciais de Rudolf Laban com as de seus discípulos. Irmgad Bartenieff acrescentou ao sistema a categoria Corpo. Hoje, o que se denomina Sistema Laban/ Bartenieff é constituído das categorias: Corpo, Expressividade, Espaço e Forma. Na proposta metodológica, trabalhei mais especificamente com as categorias Expressividade (fatores, impulsos e estados expressivos) e Corpo (Conexões ósseas, que se relacionam com as unidades da Coordenação Motora).

9 A abordagem somática Coordenação Motora foi desenvolvida a partir dos estudos da fisioterapeuta Marie-Madeleine Béziers com as parceiras Suzanne Piret (1971) e Yva Husinger (1992), pressupõe que existe estreita relação entre estrutura e função e que a motricidade é inseparável do psíquico. Para a Coordenação Motora, o corpo é constituído de unidades de coordenação, que são dois ęlementos em tensão.

10 Laban propunha ações corporais (dobrar, flexionar, contrair, estender, esticar, girar, saltar, deslocar, transferir) e ações básicas de esforço (torcer, flutuar, deslizar, socar, açoitar, espanar, pressionar e pontuar). 
adas partes do corpo com verbos e criadas frases coreográficas. A pesquisa de movimento está em acordo com um dos princípios da Educação Somática e do Construtivismo Pós-Piagetiano: a descoberta pessoal.

O eixo (re)conhecer, na maioria das vezes, diz respeito ao reconhecimento da estrutura musculoesquelética. Pode-se propor que as crianças brinquem de caminhar com diferentes apoios. Enquanto o eixo denominado conceituar é a sistematização do conhecimento - por exemplo, criação cênica, já que para o Construtivismo Pós-Piagetiano, conceituar é atribuir sentidos:

\begin{abstract}
O processo de construção de significados que, em maior ou menor medida, é realizado por alunos e alunas sobre os conteúdos de ensino, é inseparável do processo mediante o qual atribuem este ou aquele sentido aos conteúdos. [...] Os alunos constroem determinados significados sobre os conteúdos à medida que, simultaneamente, atribuem-lhes determinado sentido. (COLL; MARTíN, 2009, p. 207-208) (grifo dos autores)
\end{abstract}

Por sua vez, (re)significar pode ser trabalhar com frases coreográficas (criadas pelas crianças ou pela professora) de formas variadas: mudar a composição, alterar a dinâmica do movimento (peso, fluxo, tempo e espaço) etc.

Os eixos da proposta metodológica não necessariamente ocorrem em todas as aulas, nem ocorrem em uma ordem definida. Pode ser que em um encontro sejam vivenciados apenas um ou dois eixos, por exemplo (re)conhecimento e conceituação. Do mesmo modo que os três elementos da tríade (dança-expressividade-estrutura corporal) não precisam estar presentes em uma mesma aula, ou seja, em um dia, pode-se optar por trabalhar conteúdos relacionados de dança e estrutura corporal.

Um elemento importante é a oportunidade de pesquisar movimentos e criar frases coreográficas. Acredito que quando uma criança descobre movimentos e cria sua própria dança, vive uma aprendizagem significativa, mesmo em aulas que sejam de danças codificadas. Ao longo dos anos, o ensino da dança pouco deu oportunidade de criação tanto a crianças quanto a 
jovens e adultos, mas, como dito anteriormente, priorizou a cópia e a reprodução de movimentos. Ou seja, é muito comum, em aulas de dança - em escolas de educação básica, organizações não-governamentais ou escolas de dança - que as coreografias sejam montadas apenas pelo(a) professor(a). Aqui a proposição é que a criança construa seu conhecimento em dança e, nesta construção, crie suas danças - mesmo quando, eventualmente, reproduza uma dança proposta pelo(a) professor(a), pois sempre há a possibilidade de (re)significação.

Uma estratégia utilizada em algumas aulas é o que tenho chamado de histórias dançadas. Esta estratégia pode perpassar toda a aula ou apenas um momento. Por exemplo: em uma classe de primeiro ano do ensino Fundamental I, cujo tema gerador ${ }^{11}$ é o Universo, pode-se desenvolver toda uma aula contando a história da origem do Universo e vivendo-a dançando, a partir da exploração e pesquisa de movimento. Por outro lado, a mesma estratégia pode ser usada apenas em um momento específico da aula, como a criação de uma pequena frase coreográfica ou o uso de uma música com letra, que seja cantada enquanto se dança. Importante ressaltar que as histórias dançadas não necessariamente são narrativas com início, meio e fim, como comumente estamos acostumados(as) em histórias infantis. Pelo contrário, se a arte contemporânea não trabalha com uma narrativa linear, por que a dança produzida na contemporaneidade iria reforçar o que se fazia na dança anteriormente? Ou mais, se a própria criança não é linear (SARMENTO, 2003), por que haveríamos de ser? Neste sentido, o pensamento pós-dramático ${ }^{12}$, que trabalha com outra relação de

11 Temas geradores foram propostos por Paulo Freire, como temas que fossem significativos e problematizadores. Muitas escolas de educação infantil e do Fundamental I utilizam temas geradores. Por isso, quando desenvolvo ações dentro do currículo da educação básica, busco integrar as aulas de Dança às proposições da escola para aquela turma/ano, ou seja, as crianças aprendem dançando aqueles temas, ao mesmo tempo em que aprendem conceitos de dança. No caso do Universo, a órbita me permite trabalhar um conteúdo específico de Dança, como por exemplo, o giro, o deslocamento espacial etc.

12 O pós-dramático explora o teatro como acontecimento, não se satisfazendo em contar uma história, provocando reflexão sobre o modus vivendi social. Neste tipo de obra, o público tem mais autonomia e proximidade, tornando-se integrante do processo. Aqui transpomos o pensamento do teatro pós-dramático para a dança, que não tem uma narrativa linear, que explora a relação tempo-espaço de forma outra e que busca relação com a plateia que não apenas 
tempo e espaço, permeia o sentido das histórias dançadas.

Acredito que, quando os(as) estudantes fazem aulas passando por este caminho metodológico, compreendem que dançar não é simplesmente copiar movimentos e que conseguem perceber que existem muitas danças - tanto aquelas que existem na TV, como as já conhecidas e, mais que isso, suas danças. Nesta perspectiva, os(as) estudantes são ativos(as) em todos os sentidos e, concentrados(as) na produção de suas danças, evitam automatismos, de modo que podem, inclusive, perceberem o caminho do movimento proposto ou criado.

\section{PRODUZINDO DANÇA COM CRIANÇAS}

Além das atividades desenvolvidas nas disciplinas na Universidade - na Bahia, entre 2013 e 2016 e no Rio Grande do Sul, desde 2017 -, bem como em projetos de extensão e pesquisa que atendam infâncias, tenho me aventurado, neste ano, na produção de um espetáculo de dança para/com crianças. É a primeira vez que a Universidade irá produzir um espetáculo específico para/com este público. A ação faz parte das atividades desenvolvidas pelo PIBID/Dança. O programa tem sido desenvolvido em três escolas da cidade de Santa Maria (RS), na região central, na periferia e zona rural, em turmas de pré-escola até o último ano do Ensino Fundamental II. No entanto, o espetáculo, em gestação, é direcionado às crianças da pré-escola e Fundamental I.

As crianças da faixa etária escolhida para o espetáculo são ao mesmo tempo fontes inspiradoras, público e partícipes, uma vez que, no entendimento pós-dramático a plateia tem outra relação com a obra. Assim, durante o processo de criação do espetáculo, os(as) pibidianos(as) foram às escolas desenvolver ações com as crianças, das quais nasceram sugestões de cenas coreográficas, bem como levar proposições de cenas desenvolvidas dentro da Universidade para que a plateia fruísse e participasse.

A ideia norteadora da pesquisa nasceu do livro Estátua

como fruidora, mas como partícipe da cena. 
de Nuvens - Dicionário de Palavras Pesquisadas por Infâncias (COSTA; BANDEIRA, CORRÊA, 2017). Discutimos no grupo do PIBID/Dança quais são as palavras das nossas infâncias e, a partir delas, criamos verbetes e um pequeno dicionário nosso. Aqui é importante ressaltar o conceito de infância proposto pelos autores:

A infância surge, então, enquanto conceito-chave e mobilizador de afetos políticos e relacionais. Ao invés de uma mera fase de desenvolvimento, o infantil ressurge enquanto acontecimento de abertura ao inaudito e ao impensável, experiência capaz de inaugurar outros circuitos de relação com o mundo e com o(s) outro(s). (COSTA; BORGES; AZZOLIN, 2018, p.365)

Paralelamente, pesquisamos na internet espetáculos de dança para crianças, bem como a produção teórica sobre algumas dessas obras. A ideia era perceber que dança está sendo produzida para as crianças e, ao mesmo tempo, discutir que dança queríamos fazer. Se, como professores(as) em formação, os(as) pibidianos(as) vinham atuando como performers e entendendo as crianças como performers (MACHADO, 2010a), não fazia sentido, então, uma dança para crianças; mas, sim, com crianças.

O projeto de pesquisa do espetáculo tem se desdobrado em várias frentes, mas, do mesmo modo que a proposta metodológica de aprenderensinar dança para/com crianças, tem como fio condutor o pensamento de construção de saberes, neste caso, estéticos dançantes participativos. Ou seja, a criança não será só apreciadora - não construirá apenas saberes estéticos dançantes - mas também é participante do processo, em duas dimensões na construção das cenas: como sujeito da pesquisa de campo, quando propomos atividades nas escolas que geram movimentos dançantes que poderão estar na obra ou poderão inspirar cenas do espetáculo; e como participante da cena no ato do acontecimento teatral. Isto por que: "Pensar a produção de saberes que sejam efetivamente significativos impõe a criação de novos arranjos de 
ocupação dos espaços, de outras táticas relacionais com o outro e de dispositivos que possam acolher os efeitos destes encontros." (COSTA; BORGES; AZZOLIN, 2018, p.373) Com esse novo ir-e-vir na escola, nas duas dimensões da construção das cenas, acreditamos que estamos proporcionando a construção de saberes significativos que, neste caso, são estéticos dançantes participativos.

A partir do nosso dicionário, percebemos que muitas das nossas palavras tinham relação com brinquedos, brincadeiras e jogos que realizamos em nossas diferentes infâncias - não apenas do ponto de vista geracional, mas infâncias que cultivamos na adultez. Desta maneira, uma das estratégias de criação foi solicitar aos(às) pibidianos(as) que propusessem procedimentos a partir de suas infâncias: nasceram atividades vindas de brincadeiras como o telefone sem fio, jogos como Imagem e Ação, jogos de videogame, além de atividades a partir de brinquedos, como o bambolê, a bola de futebol e a boneca.

Desde o início do processo, a ideia é que muitas das frases coreográficas criadas a partir de nossas brincadeiras e jogos possam ter a atuação das crianças no ato da encenação. Por exemplo, uma das frases coreográficas nasceu de charadas e, então, enquanto a mesma se desenvolve, a criança participa dizendo o que acredita que seja a resposta. Por outro lado, em cenas como a que usamos os balões, a proposta é que as crianças entrem e dancem conosco e com os balões.

Ao mesmo tempo em que estamos criando nossas frases coreográficas, temos ido à escola em busca de materiais para a cena, em várias frentes. Em uma primeira ida, aproveitamos uma atividade da escola, que celebrava o mês da família, para vivenciarmos com as crianças e seus pais as brincadeiras de suas infâncias: jogo de bola de gude, dança das cadeiras, pula corda, cinco marias etc. Posteriormente, criamos atividades para as crianças, como forma de levantamento de material coreográfico: como elas dançam o que propomos? Destas ações tanto podem surgir frases coreográficas que repetiremos no espetáculo como também atividades que são realizadas na cena, para que as crianças dancem conosco. Outra frente de 
ação foi levar às escolas parceiras do PIBID as frases coreográficas já desenvolvidas para percebermos como as crianças reagem a elas e, mais que isso, como criam danças conosco a partir destas frases. A interatividade, ludicidade, fantasia do real e reiteração permeiam a nossa ação, bem como compreendermo-nos a todos(as) como performers. Neste sentido, consideramos que:

Há uma íntima correlação entre brincar, imaginar e fantasiar, e poder brincar muito durante a pequena infância é semear um enorme canteiro de obras para todos os processos imaginativos. Brincar livremente, e não "educativamente": o adulto que considera necessário moldar, modelar os comportamentos imaginativos, infelizmente também direciona os rumos do brincar, imaginar e fantasiar. (MACHADO, 2010b, p. 289)

E que, neste caso, como adultos(as), não podemos propor um brincar educativamente, mas que brinquemos todos e todas em nossas diferentes infâncias, que nos permitamos, em cena, brincar com os(as) outros(as).

O espetáculo ainda está em fase de criação, mas, o mais importante neste processo é os(as) professores(as) em formação perceberem formas outras de atuar com infâncias. E, do ponto de vista estético, que vivenciem na dança, o pensamento do teatro pós-dramático:

[...] esse modo de fazer teatro não necessita de um texto dramatúrgico pronto, fechado, com começo, meio e fim - radicalizando, prescinde até mesmo do texto - o que nos leva a um tipo de trabalho que apresenta uma bagunça, por assim dizer, entre começo, meio e fim; e nessa bagunça presenciamos rupturas, repetições, nonsense; não há lógica formal, diversas lógicas convivem, e isso implica em um tipo de recepção, por parte de quem assiste: o espectador encontra-se mais livre para interpretar, a seu modo, tudo que vive durante um ato performático. Portanto essa propositiva nos oferece uma transgressão dos gêneros, abrindo portas e janelas para outros modos de fazer teatro e de usufruir teatro - são as linguagens híbridas. (MACHADO, 2010a, p. 118) 
Ou seja, buscamos uma dança que não tenha uma narrativa linear, muito menos que tenha uma "história a contar", que a plateia seja partícipe do espetáculo - inclusive do ponto de vista da relação com o espaço, que não é um palco italiano, mas um espaço no qual a criança está em cena o tempo todo enquanto a obra se desenvolve e, em determinados momentos, é convidada a participar da cena.

Nossas infâncias atuais trabalham a partir da hibridização, do hipertexto, dos hiperlinks, do tudo ao mesmo tempo agora, sem narrativa linear, então, acredito que esta seja a forma contemporânea de produzirmos dança com crianças. Além disso, a não linearidade é uma das características das culturas das infâncias (SARMENTO, 2003) e, neste caso, o espetáculo reforça este entendimento de infâncias.

\section{(IN)CONCLUSÕES}

Nas práticas que temos executado, em projetos de extensão, nos componentes curriculares e no PIBID/Dança, tenho visto o prazer da descoberta, o prazer de dançar, a partir da proposta metodológica usada. Acredito que a proposta Espiral do/no Movimento/Conhecimento permite mudanças conceituais para professores(as) e alunos(as). Dos dois lados, vemos um modo outro de conceituar dança - e o espetáculo em gestação reforça este entendimento de muitas danças outras. Por outro lado, percebe-se, no caso dos(as) professores(as) em formação uma mudança em relação ao que significa, para eles(as) ensinar dança, bem como o que seja trabalhar com dança na escola e em outros espaços formativos. Para alguns alunos e algumas alunas, a produção da obra significa também rever seus conceitos a respeito do que seja dança cênica.

Por sua vez, entre os(as) estudantes da pré-escola e ensino Fundamental I que têm participado das nossas ações, temos percebido o desenvolvimento da autonomia deles(as), assim como a compreensão de que o(a) professor(a) não é o(a) único(a) detentor(a) do conhecimento, de que eles(as) 
também têm saberes sobre dança e que outros saberes estão sendo construídos, em comunhão. Ou seja, eles(as) compreendem, enquanto vivem a experiência, que o(a) professor(a) não vai lá para dar classes de dança e o(a) aluno(a) receber aulas de dança. Do mesmo modo que os(as) professores(as) em formação também passam a entender esta outra dinâmica do processo de aprenderensinar dança. Estamos ali, juntos(as) para criarmos nossas danças e, construirmos, juntos(as) nossos entendimentos do que seja(m) dança(s) na contemporaneidade. Somos performers em ação. Creio que estamos fazendo isto e que estamos construindo, todos e todas, nosso conhecimento no/pelo movimento.

Há que se considerar também que, apesar de valorizarmos a autoinvestigação, em todo o processo há uma relação tanto pessoal quanto grupal, de conexão com os(as) outros, na interatividade típica da infância (SARMENTO, 2003).

Acredito que proposições que revejam as formas de aprenderensinar dança permitem que revisemos conceitos a respeito do que seja dança, que criemos formas outras de atuar com dança, bem como que possamos - neste caso específico aqui discutido - propor dança com e não para. Talvez, para os(as) professores em formação, esta seja a grande mudança de paradigma. 


\section{REFERÊNCIAS}

BALDI, Neila. O que há do lado de lá? Cartas de um dueto da educação somática com o balé clássico. 2014. 156 fls. Dissertação (Mestrado em Artes Cênicas) - Escola de Teatro, Universidade Federal da Bahia, Salvador, 2014.

COLL, César; MARTíN, Elena. A avaliação da aprendizagem no currículo escolar: uma perspectiva construtivista. In: COLL, César; MARTÍN, Elena; MAURI, Teresa; MIRAS, Mariana; ONRUBIA, Javier; SOLÉ, Isabel; ZABALA, Antoni. O construtivismo na sala de aula. São Paulo: Editora Ática, 2009. p. 197-221.

COSTA, Luciano Bedin da; BORGES, Joelma de Vargas; AZZOLIN, Rita de Cássia Nunes. Uma viagem muito louca: algumas considerações sobre palavras pesquisadas por infâncias. Childhood \& philosophy. Rio de Janeiro, v. 14, n. 30, maio-ago, 2018. p. 363-383.

COSTA, Luciano Bedin da; BANDEIRA, Larissa da Veiga Vieira; CORRÊA, Tatiele Mesquita. Estátuas de Nuvens - Dicionário de palavras pesquisadas por infâncias. Porto Alegre: Sulina, 2017.

FREIRE, Paulo. Pedagogia da Autonomia: saberes necessários à prática educativa. São Paulo: Paz e Terra, 1996.

FORTIN, Sylvie. Living in movement. Development of somatics practices in different cultures. Journal of Dance Education. v. 2, n. 4, 2002. p. 128-136

PIAGET, Jean. O nascimento da inteligência na criança. $4^{a} \mathrm{Ed}$. Rio de Janeiro: LTC (Livros Técnicos e Científicos Editora Ltda), 1987.

MACHADO, Marina Marcondes. A criança é performer. Educação e Realidade. Porto Alegre, v. 35, n. 2, maio-ago, 2010a. p. 115137

MACHADO, Marina Marcondes. O imaginário infantil como 
trabalho-em-processo. Childhood \& philosophy. Rio de Janeiro, v.6, n. 12, jul-dez, 2010b. p. 282-295.

PÉREZ, Carmen Lúcia Vidal; SAMPAIO, Carmen Sanches. Conversas sobre aprenderensinar a ler a escrever: (nos) alfabetizando com crianças e sem cartilhas... In: LIBÂNEO, José Carlos. ALVES, Nilda (org). Temas de Pedagogia: diálogos entre didática e currículo. São Paulo: Cortez, 2012. p. 395-429.

SARMENTO, Manuel Jacinto. Imaginário e culturas da infância. Cadernos de Educação. Pelotas, v. 12, n. 21, 2003. p. 51-69.

STINSON, Susan. Piaget para professores de dança: um estudo teórico. Revista Mineira de Educação Física. Viçosa: v. 7, n. 1, 1999. p. 14-32. 